This dissertation has been

microfilmed exactly as received

$66-1863$

WETZEL, Allan Brooke, 1933-

VISUAL CORTICAL LESIONS IN THE CAT: A ST'UDY OF DEPTH AND PATTERN DISCRIMINATION.

The Ohio State University, Ph.D., 1965

Psychology, clinical

University Microfilms, Inc., Ann Arbor, Michigan 


\section{VISUAL CORTICAL LESIONS IN THE CAT: A STUDY OP DEPTH AND PATTERN DISCRIMINATION}

\section{DISSERTATION}

\section{Presented in Partial Fulfiliment of the Requiremente for the Degree Doctor of Fhilos ophy in the Graduate Sohool of The Ohio State University}

\section{By}

Allan Brooke Wetrel, B.S, M.A.

********

The Ohio State University

1965

Approved by

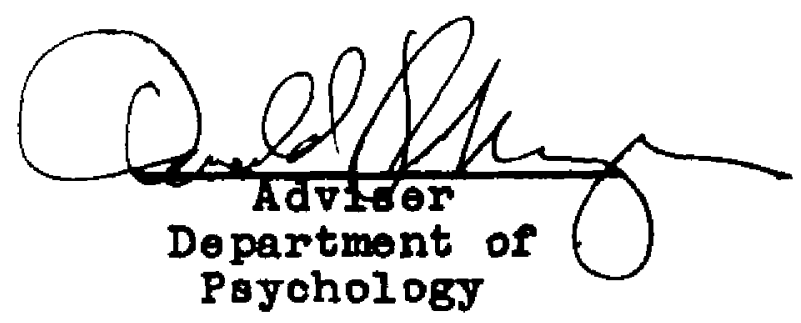




\section{ACKNOWLEDGMENTS}

The author gratefully acknowledges the constant assistance and encouragement of his adviser, Dr. Donald R. Mejor, In all phases of the study. The author also wishes to thank Dr. Raymond Miles and Dr. Wlillam C. Hcwell who served on the reading committee and were always avallable for consultation with the euthor. Pabtioular thanks is due to Dr. Patricia M. Mejer who performed some of the eurgery and who kindly consulted with the author in all pnases of the study. Venan E. Thompson and Roy A. Anderson also performed some of the surgery, and their assistance is groatly appreclated. Finally the author is grateful to the many members of the Laboratory of Comparative and Physiological Psychology who at one time or another helped in the varled tasks necessary to the investigation The study was supported by grant MB-6211-04 from the National Institutes of Mental Health. 
VIDA

May 29, 1933 Born - Dayton, Oh1o

1954 . . . B.S., University of Kentucky, Lexington, Kontucky

1955-1957. . U.S. Army

1958-1960. - Research Ass1atant to Dr. Seymour Levine, Columbus Paychiatrio Institute Hospital, Columbus, Ohio

1960-1962. - Research Assistant to Dr. Norma Besch, Columbus Psychiatric Enstitute \& Hospital, Columbus, Oh1o

1962-1964. . Teaching Ass1atant, Departmont of Psyohology, The Oh1o State UnIversity, Columbus, Oh1o

1963 . . . M.A.. The Ohio State Univere1ty, Columbus, Oh1o

1964-1965. - Researoh Assigtant to Dr. Donald R. Mejer, Laboratory of Comparative and Phyolological Psyohologo, The ohio State University, Columbus, Ohio

\section{POBLICATIONS}

Besoh, Norma F., Thompson, V.E., and Wetzel, A.B., Studies in assoclative interference. J. exp. Psychol., 63, $342-352,1962$.

Goldman, H., Alpert, M., Levino, S., Wetzel, A.B., Production of persistent diabetes insipldus and panhypopituttarism in rats. Endocrinology, 71, 36-42, 1962.

Lovine, S, and Wetzel, A.B. Infant1le axperience, atrain differences, and 2 voldance learning. J. comp. * phys101. Psychol., 56, 879-881, 1963.

Wetzel, A.B., Thompson, V.E., Horel, A., and Meyer, Patriola M., Some consequences of perlnatal lesions of the visual cortex of the cat. In preparation. 


\section{FIELDS OF STUDY}

Major Fleld: Physiological Paychology

Minor Field: Experimental Peychology 


\section{CONTENTS}

I The Problem

Page

II Introduction

3

III Subjects and Surgery

IV Apparatus and Procedure

Experiment I: The pattern problem

11

Experiment II: The visual cliff

11

Experiment III: Visual placing

12

Experiment IV: Depth disorimination and subsequent cue reduction

12

V Results

Experiment $I$

15

Experiment II

15

Experiment III

15

Experiment IV

15

H1stology

22

VI Discussion

25

VII References

28 


\section{TABLES}

Table

1 Experiment I: Positive stimulus and trials to three criterion measures.

2 Percent responses to the shallow side of the visual cliff for each cat.

3 Percentage of occasions upon which visual

placing was observed in 150 testi.

4 Experiment IV: Deep-shallow discrimination. Positive stimulus and trials to two criterion measures .

5 Experiment IV: Stimuli for which there was clear evidence of diecrimination for each lesioned cat.

6 Percentages of the dorsal lateral geniculate nuclel undegenerated in lesioned oats. 
I. The problem

General statements (Marqu1s, 1932, Teuber, 1960, Morgan, 1965) regarding the role of the visual oortex in pattern vision stress the inability of animals with complete ablations of the striate cortex to learn pattern problems. Th1s stress should not be interpreted as moaning that such lesions destroy all reactions to patterned atimul1.

Lashley's extensive work clearly demonstrated that rats which had sustained ablations of the visual cortex were unable to learn certain pattern problems (Lashley and Frank, 1934). Nonetheless, these animals wore able to Iocallze objeots in apace (Lashley 1934;. After visual cortical gyrectomles, cats can still respond with optikinetic eje movements to moving striations (Smith, 1937). Cats can also discriminate a horizontal from a vertical bar, but after the addition of a second bar to the atimuli can not do so (Smith, 1938). After testing one of two occipltally lesioned monkeys on discrimination of various patterned configurations, Kluver (1941) ooncluded that "topographical aspeots of the stimulus configuration" may be effective in determining the reactions of lesioned monkeys. Doty (1961) has reported some, although impalrod, pattern discrimination learning In cats with degenerated lateral geniculate nuale1 after 
visual decortication. Noodecorticated oats were found by Meyer (1963) to be unable to learn a stripe-check discrimination, but they could perform on a visual oliff as well as her normal group.

Hence, there seeme ample evidence that animals deprived of their cortical visual projection areas may still respond differentially to some aspects of patterned stimulation. However, in 1941 Kluver cautioned that 1t served no purpose to say that such findings were indicative of rudimentary "pattern vision" since the problem is to find the properties of various configurations which are or are not effective in determining behavior. It was the aim of this atudy to further specify and delimit these properties. 
II. Introduction

Interest in the role of cerebral cortex in vision was, according to a compreheneive roview by Marquis (1932), awakened in the first half of the 19th century by the work of Flourens. Flourens reported that ablation of one cerebral hemlsphere resulted in blindness of the eje opposite, and that after bilateral ablation blindness was complete in pigeons, rabbits or dogs. In the intervening century between these reports and Marquig' review, evidence accumulated that the blindness observed was not absolute; 11d and puplllary reflexes were noted as spared. Many experimental studies tended to restrict the primary viaual area of the cortex to the area anatomically delimited as the area striata, and in 1911, Minkowsk1 presented prec18e experimental proof of this relationship. Even before Minkowski's demonstration of visual projection on the cortex, Munk had proposed a point-to-point projection and had attempted to explain the conflicting literature and sparing of reflexes with the concept of "psychic blindness." According to his approach, the cortex served a higher Integrative funotion and injured animals could see but not "understand". the meaning of visual images. Because this general approach did not attract any considerable experimental support, and disputes continued over whether animals with cortical lesions could reoover the ablitty to react 
to objects, interest turned to the particular specification of the ablitties of animala whlch had suffered cortical ablations.

By 1932, the evidence on the visual abilities of rabbits with cerebral lesions was atill confusing; some Investigators had found them able to react to objects, others had not. Lashley, however, had begun his extensive experiments (1929 1931) with rats, and the conclusions were already clear. He found that bilateral destruction of the occipltal cortex including all of the area striata did not Impair the ability of a rat to learn a discrimination between light and dark. If the diacrimination were learned preoperatively, 1t was lost but could be relearned. Lashley was unable to find any evidenoe of a postoperative ability of the rats to form pattern discriminations. Postoperatively Laahley's rats did seom to be able to distinguish position and, to some extent, the distance of their jumping platforms .

For dogs and cats Marquis did not find the experimental evidence unoontestable, but it did seem quite onvincing that object vision was lost after bilateral striate ablation. There were suggestions that light-dark discriminations were spared and Marquis confirmed this sparing experImentally with doge.

In the monkey the evidence was not clear cut but seemed 
to indicate that object vision was impossible with large cerebral lesions. Marquis knew of no studies of light discrimf nation with monkeys.

The clinical ovidence in man indicated to Marquis that only puplllary reflexes were spered after destruction of the visual areas of the cerebrum. From these and other data whlch he c1tes, Marquis proposed that there was a phylogenetically progrossive encephalization of visual function; more and more visual functions were taken over by the cerebral cortex until in man even light-dark discrimination was toteliy dependent upon the cortex.

Research since 1932 has served more to emphasize the simflaritios of cortical visual function in rats, cats and monkeys than to indicate a progressive encephal1zation. Additionally, it seems, as Smlth (1937b, p. 360) stated "...that no distinct division of noural function is involved in the mediation of brightness discrimination and what has been discussed by Marquis as object vision."

This conclusion of Sinth's was based upon an extensive series of experiments conducted primarily with cats (1936, 1937a, 19370 and 1938). Smtth was able to demonstrate that under conditions of 1llumination and contrast comparable to those used in previous tests of object viaion, cata with ablations of the cortical projection areas did not respond to objects, whereas under conditions of high contrast in 
1llumination they were able to do so. Further, he showed that the ability of brain damaged cats to respond to light-dark diacriminations could be dismpted by a high intensity surrounding 1llumination. Smith belleved that Lashley's fallure to elnd any evidence of pattern diecrimInation in striate ablated rats was alse due to a lack of sufficient contrast within the stimali and, in 1938, was able to demonstrate the ability of cats lacking the viaual projection areas to discriminate a horizontal from a vertical bar, a condition of high spatial contrast. Earlier studies had also provided evidence of sparing of optikinetic reflexes to moving striations (Smith, 1937a).

Thus Smlth believed that there was nelther evidence for a progresalve encephalization in the mamalian series nor any evidence for a separate oncephalization of light and pattern vision; rather, the experimental findings seemed "...consistent in showing that extirpation of the striate areas, by reduoling the efriciency of the ent1re opt1c system, brings about a limlted diaturbance in different viaual functions rather than complete abolition of certain specific functions such as pattern v1sion" (1937b, p. 363). In 1941, Kluver published a study of two monkeys that had sustained occipital lobe removal. One of the concluslons of this study is widely known; Kluver found that these monkeys did not respond to differences in brightness but 
only to differences in the density of luminous flux entering the eye. There was other information concerning the discrimination of form and position obtained from these monkeys; but because the results on form vision were not obtalned after extenglve postoperative trainlng, Kluver considered them preliminary. However, he obtained defint to differential responsea to differing topographical arrangements of stimuli and clear evidence that the makeys could respond to right or left positions of lights. Kluver treated the findings separately and made no comment upon their reconclilation. Kluver also found that high room illumination eliminated the monkey's differential responses.

In 1955 , Denny-Brown and Chambers reported upon a serles of limlted cortical ablations in monkeys. Ablation of area 17 (the striate cortex) alone resulted in spering of prehensile reactions to moving objects, in no recognition of still objects and in sparing of visual placting and opt1c righting. They too found that bright illumination inhibited the reactions. In this preparation the lateral geniculate nucleus was completely degenerated. Removal of the secondary projection areas (18 and 19) also left placing, righting and prehensile reactions intact but seemed to lead to impairment of spatial judgement and to confusion by moving objects.

A further theoretical argument has been advanced by 
Doty (1961). He has proposed that the topographical arrangement of the retino-cortical projeotion is in itself of minor or no importance in the viaual analjsis of geometrio patterns. To support this argument he has presented data from neonatal-and adult-operated cate which ind loate that cortex other than the area striata (anatomioally a point-to-point projection area) is necesaary for visual pattern discrimination. Although Doty has not precleely speoffled the necessary areas for pattern vision, he has indicated that areas lateral to the primary cortical profections may be essential for pattern discrimination. Meyer (1963) has reported that cats with ablations of most of the neocortex were unable to learn a pattern problem involving a local brightness controlled discrimination between striped and checked patterns. These cate performed auccessfully in a light avoldance task and did not differ from the normal group in responses to a visual cliff. Although there are many cues to depth in a natural situation the arrangement in this case seemed to have allowed the response to be based only upon some type of perception of pattern.

Depth discriminations and even visual placing reactions might reasonably be assumed to be dependent upon much the same mechanisms as pattern discrimination (see Gibson and Walk, 1960, on the importance of textural cues in the visual 
cliff). Hence a reasonable approach to charaoterizing the contributions of the visual cortex to the elscrimination of patterns seemed to $11 \theta$ in a comparison of depth and pattern problems. It also seomed reasonable to investigate vialal placing reactions aince in brain damaged cats Smith had found them absent (1936) while In Doty's animals they were present (1961). In Meyer's neodecorticate cats they were absent under normal conditions but recoverable under the Influence of dl-amphetamine (Meyer, Horel and Meyer, 1963). 
III. Subjects and ourgery

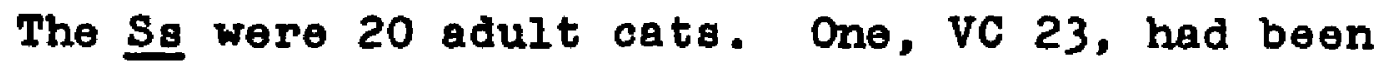
tralned on the stripe-oheck disorimination prior to surgery.

In 10 cato, cortex from the lateral and suprasylvian gyr1 was aseptically removed by subplal aspiration under sodium pentobarbital anesthesia. The lesions wero intended to encompass the striate cortex and all secondary projection areas defined by Buser and Borenstein (1959) except those on the ectosylvian gyrus. The cats were allowed at least six weeks recovery before testing. 
IV. Apparatus and procedures

The ten operated cats were tested simultaneously with the normal control $\underline{\mathrm{Sg}}$ on a variety of tasks. Essentially these tasks involved a pattern problem, responses to a visual cliff, visual placing and performance upon a horlzontal adaptation of a visual cliff to a conventional discrimination task in which the multiple cues associated with visual cliff performance could be controlled and reduced to their pattern components.

Experiment I

The normal (NC) and operated (VC) cats were allowed 500 trials to discriminate striped from checked doors (cf. Meyer, 1963) in a Yerkes-Watson-Munn box similar to that described by Aarons and Reisen (1959). Hinged stimulus doors, which concealed 2-gm. pleces of flsh, were lighted from above and positioned according to a cellerman-type serles. After preliminary training with white doors, the cata were given 10 correction trials per day for 5 daye per week unt1l 500 trials or a criterion of 18-correct-out-of20 wa reached.

Experiment II

A glass-covered $24 \times 48 \times 30$ in. black-and-whitechecked plywood box with a translucent plexiglass checked floor served as a visual cliff. The cheoks, like the checks on one of the doors in Exp. I, were $3 \times 3$ in. A trapezoldal 
starting platform 6-1n. high, and sot atop the glass, d1vided the box. On one side of the platform, a plexiglasa floor was set immediately below the glase (shallow side); while on the other, 1t rested 30-1nches underneath the glase (deep side). The cats were placed on the platform and allowed to descend to the glass on whichever side they chose once a day for 18 days. Three conditions of luminance (shallow and deep respectively 0.87 and 1.78 log. ft. lamberts; both 1.78 log. ft. lamberts; and shallow and deep reapectively 1.78 and 0.87 log. ft. lamberts) and right and left positions of the shallow side were varled according to a latin square.

\section{Experiment III}

The cats, supported as to permit them only to place by way of vigual cues, were presented to tooth-edged boards within a grey booth 15 times a day for 10 days. Randomly ordered presentations of three boards (black, grey or white) at three heights (24, 36 or 48 inches) or no boards controlled stereotyped responding.

Experiment IV

Transilluminated, 30-1n. deep black-and-whlte checked boxes replaced the $9 \times 12$ in. hinged stimulus doors in the discrimination box for this experiment. Dispensers directly over the stimuli dropped the relnforcements (2-gm. pleces of fish) in front of the stimil. After 10 days of 
preliminary training with white atimuli, the oato were reinforced for a response to elther a checked pattern directly bohind (shallow) the clear plexiglass front of the stimulus boxes or to one placed at a distance of 30-1n. (deep) from the front.

During this training to a 45-correct-out-of-50 criterion, the total amount of light from each stimulus remalned equal. The luminance on the shallow and deep sides respectively were 1.4 and $2.510 g$ ft. lamberts from the white portions. Testa were then made with the luminance of both st1mul1 at 1.4 log. It. lamberts. If a cat did not achieve $9 / 10$ correct on the test within 30 trials, it was returned to the original probiem and retrained to a $9 / 10$ criterion, then retested. All subsequest brightness or loogl brightness tests were conducted in the same manner.

A succession of brightnesa tests were conducted after completion (criterion, $9 / 10$ on any one day) of each previous test. To minimize, If not eliminate, the illumination gradient along the sides of the deep box, the st1mull were Pront-as well as trans-1liuminated. Rhoostat settings were reversed (deep, 2.5 log. ft. lambert; shallow, -0.1 log. ft. lamberts) and then a test was oonducted with luminanoe matched, the front 11 ghts on, but the black and white portions of the stimali interchanged. 
looal brightness tests, a second problem was presented. The shallow stimulus ( $3 \times 3$ in. checks) remained the same but a two-dimensional projection of the deep stimulus, presented Imediately behind the clear front panels, was subst1tuted for the deep stimulus.

If a cat was able to discriminate these stimull and discrimination was not disrupted by local brightness testa, a panel containing $1 \frac{1}{4}$-inch checks was substituted for the simulated doep stimulus.

If the cat discriminated these stimuli through local brightness tests, four orientations of $1 \frac{1}{4}$ Inch stripes were substituted for the small checks and, finally, four orlentations of 3-inch wide stripes were substituted for the smaller stripes (a problem similar to that of Experiment I). H1stology

After the behavioral testing was complete, the operated animals were perfused with saline and $10 \%$ formalin and their breins were then removed and flxed in $10 \%$ formalin. The leslons were diagramed and the brains were photographed under an ultraviolet light source whlch accentuated the contrast between the damaged and undamagec areas. The braine were embedded in celloldin and sectloned at 30 microns. Every twentieth coronel section through the lesion and every fifth section through the lateral genfoulate nuclel was stained with oresylecht violet. 
V. Regults

Experiment I

Table 1 gives the positive stimalus and the number of trials to three criterion meagures for each oat. All of the operated antmals were severely impaired in diacriminating otripes from checks. However, three of the vC cate showed some evidence of learning, and of these the antmal (vC 23) which had had prooperative training performed best.

Experimont II

Elght of the 9 normal animals descended oonsistently on the shallow side of the visual cliff. Cat NC 2 position responded. The operated cats, however, made signifloantly $\left(U=U_{4}, p<.02\right)$ more responses to the deep a1de. Luminance variations did not affect the cholcer indicated in Table 2. Experiment III

A11 15 cats visually placed. The normal cats were somewhat inconsigtent and the difference between the groups was not signifioant $(t=1.44$, df $=13$ ). The percentages of placing reactions observed during 150 testa per animal are presented in Table 3.

Experiment IV

In the first day's session of the deep-shallow disorimInation task 7 of 8 normal cats chose the deep side more than half of the 10 trials. Only VC 15 and VC 17 showed this preference in the decorticate group. 
TABLE 1: Experiment I: Triels to 3 criterion measures.

\begin{tabular}{|c|c|c|c|c|c|}
\hline & & $\begin{array}{l}\text { ositive } \\
\text { timulus }\end{array}$ & $\begin{array}{c}\text { Criterion } \\
1\end{array}$ & $\begin{array}{c}\text { Criterion } \\
2\end{array}$ & $\begin{array}{c}\text { Criterion } \\
3 \\
\end{array}$ \\
\hline \multirow{9}{*}{$\begin{array}{l}\text { Normal } \\
\text { cats }\end{array}$} & NCI & cheoks & 31 & 80 & 80 \\
\hline & NC2 & stripes & 28 & $-d$ & - \\
\hline & $\mathrm{NC} 3$ & checks & 81 & 370 & 370 \\
\hline & $\mathrm{NC}_{4}$ & checks & 90 & 90 & 190 \\
\hline & NC 5 & stripes & 242 & 440 & 470 \\
\hline & NC 6 & otripes & 377 & 380 & 380 \\
\hline & NC7 & stripes & 167 & 310 & 420 \\
\hline & $\mathrm{NC8}$ & checks & 362 & 430 & - \\
\hline & NC9 & checks & 94 & 210 & 310 \\
\hline \multirow{9}{*}{$\begin{array}{l}\text { VIsualiy } \\
\text { decorti- } \\
\text { cated } \\
\text { cats }\end{array}$} & VCI5 & checks & 344 & $\overline{-}$ & - \\
\hline & $\operatorname{vc16}$ & stripes & - & - & - \\
\hline & VCI 7 & stripes & - & - & - \\
\hline & $\mathrm{VCl} 8$ & checks & - & - & - \\
\hline & $\operatorname{VC19}$ & checks & - & - & - \\
\hline & VC20 & checks & - & - & - \\
\hline & $\mathrm{VC} 21$ & checks & 423 & - & - \\
\hline & VC22 & stripes & - & - & - \\
\hline & vc23 & checks & 73 & 430 & 430 \\
\hline
\end{tabular}

a Criterion 1: 9-out-of-any-10 correct. Touching of incorrect door recorded as an error.

b criterion 2: 9-correct-1n-any-10-trial-session. Touching of incorrect door recorded as an error.

c Criterion 3: 9-correct-of-any-10-trial-session. Incorrect alley entry recorded as an error.

d Did not meet criterion in 500 trials. 
TABLE 2. Percent responses to the shallow side of the visual cliff for each cat.

\begin{tabular}{|c|c|c|c|c|c|c|c|c|}
\hline NCI & NC2 & $\mathrm{NC4}_{4}$ & $\mathrm{NC5}$ & NC6 & NC7 & NC8 & NC9 & NCIO \\
\hline 100 & 61 & 100 & 100 & 100 & 100 & 100 & 100 & 100 \\
\hline \multicolumn{9}{|c|}{ Visually decorticated cats } \\
\hline$\overline{V C 15}$ & VC16 & VCI7 & VC19 & VC20 & VC2I & VC22 & VC23 & VC24 \\
\hline 100 & 94 & 61 & 39 & 33 & 78 & 61 & 39 & 78 \\
\hline
\end{tabular}


TABLE 3. Percentage of occasions upon which visual placing was observed in 150 tests.

Normal cats

NC1 NC2 NC4 NC5 NC6 NC7 NC8 NC9

$\begin{array}{llllllll}82 & 99 & 87 & 84 & 96 & 71 & 87 & 34\end{array}$

Viavaliy decorticated cats

VCI5 VCI6 VCI9 VC2O VC2I VC22 VC23

$\begin{array}{lllllll}38 & 75 & 75 & 25 & 88 & 94 & 41\end{array}$


As Table 4 indicates, normal cats learned the deepshallow discrimination quickly. The visually decorticated cats also learned the discrimination but required many more trials.

Two cats (VC 16 and vC 22) did not meot criterion within 500 trials, but after special training did discriminate these stimali. In this training vc 16 first learned a black-white discrimination; then, after training with combined depth and brightness cues, VC 16 was et111 abie to discriminate when the brightness cues were removed. Cat VC 22 responded differentlally to the depth oues but always first entered the left alley. Thus, if reinforcement was witheld for 5-sec., and the left stimulus was positive, the cat waited in that alley. If the left stimulus was negative, the cat went to the other stimulus in less than 5-sec. Indications of differential responding hence were obtained by timing the oat's left alley reaponse in further testing.

Cat VC 23 did not meet a 45-correct-out-of-50 oriterion in 1000 trials and was not further tested. Cat vC 17 died before testing was complete.

Changes in lighting affected only the performance of vC 20. However, after extensive training with gradual changes in lighting, its performance became independent of any changes. Reversal of the black and white portions of the stimuli had no effect with any oat. 
TABLE 4. Experiment IV: Deep-shallow discrimination. Posit1ve stimalus and trials to two criterion measures.

\begin{tabular}{|c|c|c|c|c|}
\hline & & $\begin{array}{l}\text { Positiro } \\
\text { stimulus }\end{array}$ & $\begin{array}{c}\text { Criterion } \\
3\end{array}$ & $\begin{array}{c}\text { Criterion } \\
4\end{array}$ \\
\hline \multirow[t]{8}{*}{$\begin{array}{l}\text { Normal } \\
\text { cats }\end{array}$} & NC1 & shall Dw & 40 & 50 \\
\hline & $\mathrm{NC2}$ & shallow & 30 & 210 \\
\hline & $\mathrm{NC}_{4}$ & deep & 0 & 150 \\
\hline & NC5 & deep & 0 & 230 \\
\hline & NC 6 & deep & 40 & 30 \\
\hline & NC7 & shallow & 120 & 150 \\
\hline & NC8 & shallow & 20 & 20 \\
\hline & NC9 & deep & 10 & 130 \\
\hline \multirow{8}{*}{$\begin{array}{l}\text { Visually } \\
\text { decorticated } \\
\text { cate }\end{array}$} & VC15 & shallow & 80 & 170 \\
\hline & VC16 & shallow & $-c$ & $-c$ \\
\hline & VC17 & deep & 270 & Died \\
\hline & vc19 & deep & 390 & 460 \\
\hline & $\mathrm{VC2O}$ & shallow & 440 & 440 \\
\hline & VC21 & deep & 140 & 320 \\
\hline & VC22 & ahall ow & $-c$ & $-c$ \\
\hline & $\mathrm{VC} 23$ & shallow & 490 & $-d$ \\
\hline
\end{tabular}

a Criterion 3: 9-of-any-10-trial-session correct. Incorrect alley entry recorded as an error.

b Criterion 4: 45-of-50-trials in five sessions correct. Incorrect alley entry recorded as an error.

c Mot oritorion artor spocial training.

d Did not meet criterion in 1000 trials. 
When a two-dimensional projection of the deep atimulus was substituted for the deep stimulus proper, all normal and 5 of the 6 remaining decorticates met criterion (9-correct-out-af-10) within 60 trials. Cat VC 22 met criterion at 400 trials but 1 ts performance was unstable during testing with reversals of the black-white portions of the stimuli. No determination of the influences of these cues could be made and the cet was not further tested.

When the $1 \frac{1}{4}-1$. check pattern was substituted for the two-dimensional projection of the deep stimulus, all normal and 3 decorticated (VC 15, VC 19, VC 21) Sa again transferred quickly. Cat VC 16 met criterion after 240 trials, but its performance was unstable and no determination of the influence of brightness cues could be made. Cat ve 20 could not discriminate these stimuli within 310 trials.

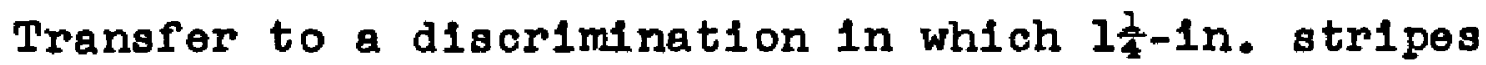
were substituted for the $1 \frac{1}{4}-1 n$. checks was more difficult (one normal cat required 190 trials). Three operated cats were tested; VC 21 did not meet criterion in 510 trials. Although VC 19 met criterion 1 ts performance was unstable and the influence of brightness cues could not be determined. The remaining operated cat (VC 15) was able to discriminate these stimuli and the 3-1n. stripes from 3-1n. checks. Although unstable performance sometimes accompanled the brightness variation in this experiment, there was no 
clear evidence that any cat was responding to local brightness cues. Overhead 11ghting rather than transillumination had no effect.

A summary of the results from operated cats in this phase is given in Table 5. All normal cats discriminated these stinul1.

Histology

The extent of the striate cortical lesions was judged by examination of retrograde degeneration in the dorsal lateral geniculate nucle1. Table 6 presents the percentages of spering of the cells within these nuclel except in the instance of vC 24, which died unexpectediy.

Rank-order correlations of visual cliff, visual placing and Experiment IV performance with the extent of lateral genlculate demage were obtained. The correlation between visual placing and lesi on extent was not signif1cant $\left(r_{g}=+.66, p>.05\right)$. Significant correlations were obtalned between visual-cliff performance and lesion extent $\left(r_{8}=+.87, p<.01\right)$ and ultimate performance in Experiment IV and lesion extent $\left(r_{s}=+.75, p<.05\right)$. 
TABLE 5. Exporiment IV: Summary performance for each lesioned cat. "D" Inidcates succesaful completion of the problem and local brightness tests. Normal cats were successful on all problems .

\begin{tabular}{|c|c|c|c|c|c|}
\hline & $\begin{array}{l}\text { Deep } \\
\text { vs. } \\
\text { shaliow }\end{array}$ & $\begin{array}{l}\text { Large checks } \\
\text { vs simulat - } \\
\text { ed deep }\end{array}$ & $\begin{array}{l}\text { Small vs. } \\
\text { large } \\
\text { checks }\end{array}$ & $\begin{array}{c}\text { Small gtripes } \\
\text { va. large } \\
\text { cheoks }\end{array}$ & $\begin{array}{l}\text { Stripes } \\
\text { vs. } \\
\text { checks }\end{array}$ \\
\hline vC15 & $\mathrm{D}$ & D & D & D & D \\
\hline $\operatorname{vcl} 6$ & $\mathrm{D}$ & $\mathrm{D}$ & & & \\
\hline vc19 & D & $D$ & D & & \\
\hline VC20 & $\mathrm{D}$ & D & & & \\
\hline VC2l & D & D & D & & \\
\hline vc22 & D & & & & \\
\hline $\mathrm{VC2} 3$ & & & & & \\
\hline
\end{tabular}


TABIE 6. Percentages of the dorsal lateral genfculate nuclel undegenerated in lesioned cats.

\begin{tabular}{lllll}
$\begin{array}{l}\text { Legioned } \\
\text { cat }\end{array}$ & $\begin{array}{c}\% \\
\text { spered, } \\
\text { left }\end{array}$ & $\begin{array}{l}\text { Left nucleus: } \\
\text { location of } \\
\text { sparing }\end{array}$ & $\begin{array}{l}\% \\
\text { spared, } \\
\text { right }\end{array}$ & $\begin{array}{l}\text { Right nucleus: } \\
\text { location of } \\
\text { sparing }\end{array}$ \\
\hline vC20 & 0 & & 4 & anterior ventral
\end{tabular}

ve23 8 anterior ventral, 4 posterior dorsoposterior dorsolateral

VC19

11 anterior, anterior 14 ventral, posterior lateral

ve16

anterior, anterior

10

anterior ventro-lateral, posterior

vc22

12

anterior ventral 20

anterior \& posterior

vc21

35

anterior \& anter- 22

enterior lor lateral

VCl7 60 anterior, anterior 36

anterior ventral, ventral, \& ventro\& ventro-lateral

$\operatorname{vc18}$

57 anterior dorsolateral, lateral \& posterior

anterior, anteriorventral, posterior lateral

ve15 18 posterior ventral 80

65 anterior lateral, \& posterior

anterior, ventral \& posterior 
VI. D1scussion

In review, these lesioned cats were able to perform certain behaviors which appear to be dependent upon a modicum of form perception. They were least impaired in visual placing, a performance which was not expected to be spared except in preparations which were subtotal (Bard and Orlas, 1933). At least some portions of the LGN's were intact in all the present operated group; however, VC 20 with the most complete ablation and only $4 \%$ of the right LGN remaining placed on $25 \%$ of the tests.

Visual cliff performances were more impaired than those observed by P.M. Meyer (1963), desplte the fact that her cats had sustalned ablations of more cortex. However, the test methods differed; in Meyer's cliff, deep cholces were punished by a fall, whereas in this experiment the consequences of a cholce were 1dentical. The difference in results may be a function of these situation differences since cats in the present study could distinguish deep from shallow stimuli in a discriminatinn situation.

The oate were severely Impaired in the check versus stripe problem. Two operated cats with considerable cortical sparing met only a weak criterion. VC 23, which learned, had little cortical sparing but was unique in 
that it had had extensive prooperative training on the problem.

However, cats that falled this problem did discriminate between the deep and shallow alleys and transferred that ilscrimination (with the exception of VC 23 and VC 22) to the check versus two-dimensional projection of the deep stimulus problem.

The question, then, 1s whether the configuration of the cues in a two-dimensional projection of a cliff or the deep and shallow alleys needs to be appealed to as a factor in sparing of discrimination. If so, then the lesioned animals should not have transferred to the $1 \frac{1}{4}-$ in. checked pattern. However, 3 of 5 animals did transfer. Two of these subsequently failed to trensfer to the $1 \frac{1}{4}-1$ n. atripe problem and this problem was successfully completed by only the cat which had $80 \%$ of the LGN apared unflaterally.

The most pargimonious assumption is that these results are all consistent with the view that animals with striate lesions still are capable of visual discriminations of. stimuli which contain different contour lengths. This is a common property of all the discrimination problems in the study.

Contour length varied even in problems which most lesioned cats falled. However, the ratios of contour difference were not the same in all problems. In the 
atripe-check problem this contrast in total contour length was highly varlable because of the use of multiple stimuli for local brightness control and the mean ratio of differences was $1: 2$. The contrast was also variable and very small (mean $1: 1,3$ ) in the $1 \frac{1}{4}-1 n$. stripe-3-1n. check problem which only one lesioned cat discriminated. The other problems had constant and larger ratios; the ratio in the $1 \frac{1}{4}-1 n .-3-1 n$. check problem was $1: 2 \cdot 3$ and in the two-dimensional projection situation was $1: 4.3$.

Hence the correlation of lesion extent with ultimate performance in Experiment IV appears to indicate that ability to discriminate contour differences is decreased by more and more severe geniculo-striate ablation in these cats.

Simllarly, Welskrantz (1963) found that a young monkey with striate cortex ablation could discriminate stimuli which differed substantially in total contour length. Interestingly, one of the occlpitally lesioned monkeys tested by Kluver (194I) was able to discriminate a square from a configuration of 76 circles having the same total area, but not a square from a cross of equal area. 


\section{REFERENCES}

Bard, P. \& Orias, 0 . Localized oortical management of visual and labyrinthine placing reactions. Amer. J. Physiology, 1933, 105, 2-3.

Bueer, P. \& Borenstein, P. Responses somés thésiques, visuelles ot auditives recuelliles au niveau du cortex kassociatif» suprasjlvian chez le chat curarise non anesthesié. EEG Clin. Neurolphysiol., 1959, 11, 285-304.

Doty, R.W. Functional significance of the topographical aspects of the retino-cortical projection. In $R$. Jung and H. Kornhaber (Eds.), The V1aual System: Nourophy $1010 \mathrm{gy}$ and Paychophysica. Berlin: SpringerVerlag, 1961, pp. 228-247.

Denney-Brown, D. \& Chambers, R.A. Vlsuomotor function in the cerebral cortex. J. nerv. ment. Dis., 1955, 12I, 288-289.

Glbson, Eleanor J. \& Walk, R.D. The "visual cliff". Sc1. Amer., 1960, 202, 64-71.

Kluver, H. V1sual functions after removal of the occlpital lobes. J. Paychol., 1941, 11, 23-45.

Lashley, K.S. Brain Mechanisms and Intelligence Chicago: Univ, of Chicago Press, 1929.

Lashley, K.S. The mechanism of vision: IV. The cerebral areas necessary for pattern vision in the rat. $J$. comp. Neuro1., 1931, 53, 419-478.

Lashley, K.S. The mechantsm of vision: XIV. Visual percep$t i$ on of distance after injuries to the cerebral corbex, colliculi, or optic thalamus. J. genet. Psychol., 1934, 45, 1936-144.

Lashley, K.S. \& Frank, M. The mechanism of viston: X. Postoperative disturbances of hahits based on detail vision in the rat after lesions of the cerebral visual areas. J. comp. Paychol., 1934, 17, 355-380.

Marquis, D.G. Effect of removal of the visual cortex in manmals with observations on the retention of light discrimination in dogs. Proc. assn. nerv. ment. Dis., 1932, 13, 558-592. 
Meyer, Patricia M. Analysis of visual behavior in cats with extensive neocortical ablations. J. comp. physiol. Psychol., 1963, 56, 397-401.

Meyer, Patricia M., Horel, J.A. \& Meyer, D.R. The effects of di-amphetamine upon placing responses in neodecorticate cats. J. comp. physiol. Psychol., 1963, 56, 402 .

Morgan, C.T. Physiolog1cal Paychology, McGraw Hill: New York, 1965, p. 194 .

Smith, K.U. The effect of extirpation of the striate cortex upon visually controlled palpebral reactions, compensatory eje movement, and placing reactions of the fore$11 \mathrm{mbs}$ of the cat. Psychol. Bull., 1936, 33, 606-607.

Smlth, K.U. The postoperative effects of removal of the atriate cortex upon certain unlearned visually controlled reactions in the cat. J. genet. Psychol., $1937,50,137-156$. (a)

Smith, K.U. Viaual discrimination in the cat: V. The postoperative effects of removal of the striate cortex upon intensity discrimination. J. genet. Psychol., 1937, 51, 329-365. (b)

Smith, K.U. Viaual discrimination in the cat: VI. The relation between pattern vision and visual acuity and the optic projection centers of the nervous system. J. genet. Paychol., 1938, 53, 251-272.

Teuber, Hans-Lukas Chapt. LXV, Perception, in John Fleld (Ed) Handbook of Physiology, section i, volume III, Baltimore: Waveriy Press, 1960, p. 1614 .

Welakrantz, Lawrence Contour discrimination in a young monkey with striate cortex ablation. Neuropsychologia, 1963, 1, 145-164. 